\title{
Worldwide distribution of the modiomorphid bivalve genus Caspiconcha in late Mesozoic hydrocarbon seeps
}

Robert G. Jenkins, Andrzej Kaim, Crispin T. S. Little, Yasuhiro Iba, Kazushige Tanabe, and Kathleen A. Campbell

Acta Palaeontologica Polonica 58 (2), 2013: 357-382 doi: http://dx.doi.org/10.4202/app.2011.0026

Exceptionally well preserved specimens of the bivalve mollusc Modiola major were collected from a Lower Cretaceous (Barremian) hydrocarbon seep deposit in northern California. This material, together with the type series of M. major, and various other specimens from Upper Jurassic to Lower Cretaceous seep localities in California, is redescribed and referred to the hydrocarbon seep-restricted modiomorphid genus Caspiconcha. We include also a description of Myoconcha americana because some previous reports have incorrectly synonymized Myoconcha americana with Caspiconcha major. In addition, we report Caspiconcha sp. from a Lower Cretaceous (Albian) hydrocarbon seep from Hokkaido, Japan, and we review all currently described species of Caspiconcha, and other species that probably belong to this genus. We demonstrate that Caspiconcha had a widespread distribution in Late Jurassic to Early Cretaceous hydrocarbon seeps, but became rare thereafter, with the last representative occurring in Upper Cretaceous strata of Japan. This macroevolutionary pattern is similar to that observed in the seep-restricted brachiopods. After the decline of Caspiconcha at the end of the Early Cretaceous and its last occurrence in the Campanian, the ecological niche of epifaunal to semi-infaunal seep endemic bivalves was largely vacant and not reoccupied until the Eocene with the appearance of the vesicomyid and bathymodiolin bivalves. The formal placement of $M$. major into the genus Caspiconcha restricts the fossil record of mytilids at seeps to post-Mesozoic times, and thus there is less discrepancy between the fossil record of chemosynthetic mytilids and their divergence age estimates from molecular data.

Key words: Bivalvia, Modiomorphidae, Kalenteridae, chemosynthesis-based ecosystem, cold seeps, Mesozoic, California, Japan.

Robert Jenkins [robertgj@ staff.kanazawa-u.ac.jp], Graduate School of Environment and Information Sciences, Yokohama National University, Yokohama 240-8501, Japan and Bayerische Staatssammlung für Paläontologie und Geologie, 80333 München, Germany; Andrzej Kaim [kaim@twarda.pan.pl ], Institute of Paleobiology, Polish Academy of Sciences, PL-00-818 Warszawa, Poland and Bayerische Staatssammlung für Paläontologie und 
Geologie, 80333 München, Germany; Crispin T. S. Little [C.T.S.Little@earth.leeds.ac.uk ], School of Earth and Environment, University of Leeds, Leeds LS2 9JT, United Kingdom; Yasuhiro Iba [iba@mail.sci.hokudai.ac.jp], Hokkaido University of Education, Kushiro 085-8580, Japan; Kazushige Tanabe [tanabe@um.u-tokyo.ac.jp ], Department of Earth and Planetary Science, University of Tokyo, Tokyo 113-0033, Japan; Kathleen A. Campbell [a.campbell@auckland.ac.nz], School of Environment, The University of Auckland, Auckland 1142, New Zealand and California Academy of Sciences.

This is an open-access article distributed under the terms of the Creative Commons Attribution License (for details please see creativecommons.org), which permits unrestricted use, distribution, and reproduction in any medium, provided the original author and source are credited.

Foris Full text $(2,451.4 \mathrm{kB})$ 